\begin{tabular}{|c|c|c|c|}
\hline $\begin{array}{l}\text { Cose Reports in } \\
\text { Intaly }\end{array}$ & $\begin{array}{l}\text { Case Rep Oncol 2010;3:212-217 } \\
\text { D0I: 10.1159/000317419 }\end{array}$ & Published online: July 3, 2010 & $\begin{array}{l}\text { @ } 2010 \text { S. Karger AG, Basel } \\
\text { ISSN 1662-6575 } \\
\text { www.karger.com/cro }\end{array}$ \\
\hline
\end{tabular}

\title{
Soft-Tissue Localization of Hepatoid Adenocarcinoma: First Case Report
}

\author{
Francesca Fornasa \\ Department of Radiology, Fracastoro Hospital, San Bonifacio, Italy
}

\section{Key Words}

Hepatoid features · Hepatoid adenocarcinoma - Lung neoplasms · Soft tissue neoplasms

\begin{abstract}
Hepatoid adenocarcinoma (HAC) is a rare type of extrahepatic cancer, whose pathologic features are indistinguishable from those of hepatocellular carcinoma. About thirty cases, nearly half of which occurring in the lung, have been described in patients with a normal liver. No imaging features are typical enough to allow a correct diagnosis. A localization of HAC in the soft tissues of the shoulder with invasion of the scapula in a woman without other symptoms is reported in this paper; soft-tissue HACs have never been described to date. An associate pulmonary HAC was eventually found in this patient.
\end{abstract}

\section{Introduction}

Hepatoid adenocarcinoma (HAC) is a very unusual histological type of primitive extrahepatic cancer. HAC can virtually never be distinguished at pathologic examination, on the basis of morphology alone, from hepatocellular carcinoma, whose gross and microscopic features (sheet-like or trabecular proliferation of neoplastic cells with abundant, eosinophilic cytoplasm, arranged in a solid pattern with sinusoid-like spaces lined by endothelium) it shares [1]. A final differential diagnosis can be obtained, in most cases, only through immunohistochemistry [2]. As possible origins of this tumor, cancer arising from ectopic liver cells embedded in the organs where HAC develops and neoplastic transformation of persistent germ cells or of nonhepatic epithelium capable of multipotential differentiation have been hypothesized [1].

The majority of HACs produce alpha-fetoprotein, whose plasma levels may be very high; however, some cases have been described in whom alpha-fetoprotein was normal.

HAC occurs in patients with no history of hepatic disease, alcoholism or addiction to other potential sources of hepatic damage; their livers demonstrate no functional or 
morphological abnormalities. Blood samples do not reveal elevated levels of hepatic enzymes, and imaging examinations fail to detect any major alteration as to volume and structure of the liver, except in the cases where hepatic metastases develop. If a liver specimen is obtained, normal features are demonstrated at pathology.

No more than 30 HACs, to our knowledge, have been reported to date. Twelve of them, in most cases leading to a poor prognosis, occurred in the lungs [1-8]; moreover, 2 histologically inhomogeneous pulmonary cancers have been described containing scattered hepatoid foci $[9,10]$. The majority of extrapulmonary HACs occur in the stomach [11], while 1 or 2 cases each were found in the mediastinum, esophagus, gallbladder, pancreas, ampulla of Vater, renal pelvis, bladder, endometrium, ovary, and testicle [12-15]. We were not able to find, in the English literature, any published paper reporting soft-tissue localizations of HAC.

\section{Case Report}

A 68-year-old nonsmoker, nonalcoholic woman, who did not report any exposition to agents inducing liver damage and who had no history of hepatic or pulmonary disease nor of any kind of cancer, underwent a conventional radiography of her left shoulder, complaining of localized pain. An ill-defined radiolucent area (fig. 1a), expression of osteolysis, was found within the scapula. A magnetic resonance examination of the shoulder was therefore performed a few days later, which demonstrated a large $(8 \times 5.5 \times 4.5 \mathrm{~cm})$ smooth-margined mass, moderately inhomogeneous and fairly enhancing after intravenous administration of paramagnetic contrast medium, infiltrating the scapular girdle both in its muscular (mainly in the supraspinatus muscle) and in its bony component (fig. 1b, c), confirming the radiographic finding and indicating a malignant soft-tissue mass with adjacent bone invasion. Ultrasound-guided fine-needle aspiration biopsy of the soft-tissue mass showed malignant cells in a trabecular pattern containing biliary thrombi (fig. 2); these features were considered by the pathologist a clue to the diagnosis of a soft-tissue localization of a hepatocellular carcinoma.

No significant abnormalities were found in blood samples: in particular, hepatic enzymes, the other liver function parameters and the serum level of alpha-fetoprotein $(2.4 \mathrm{ng} / \mathrm{ml})$ were all normal. Moreover, at both ultrasound and computed tomography (CT) examinations the liver had normal size and margins, with normal hepatic vessels; no focal lesions were detected and echotexture and density were homogeneous. A $4.5 \times 4 \times 4 \mathrm{~cm}$ solid, partly inhomogeneous mass with pleural adhesion was, however, found at CT in the upper lobe of the left lung (fig. 3 ), without regional lymphadenopathies nor further localizations. Pathologic examination of a CT-guided biopsy of the pulmonary mass revealed hepatocellular carcinoma-like neoplastic tissue whose pattern was undistinguished from the specimen obtained in the soft-tissue mass. A double localization of HAC, in the lung and in the soft tissues of the shoulder, was therefore diagnosed, the latter presumably being a metastasis from the former.

The patient underwent chemotherapy. Fifteen months after the diagnosis, she is alive and symptomfree; the size of both the soft-tissue and the pulmonary lesions has significantly reduced and no further localizations have appeared in any other organ or in the lymph nodes.

\section{Discussion}

Due to its low prevalence, HAC is never taken into consideration when an extrahepatic mass is found at imaging or endoscopy. One might suspect that in some cases of HAC the correct diagnosis is not achieved, particularly in the elderly or in patients with severe underlying disease, in whom the diagnostic workout sometimes concludes with a generic cytological ascertainment of the presence of malignant cells within a lesion.

In addition to its rarity, HAC may be underdiagnosed because of the absence of unequivocal imaging features. In the only paper published in the radiological literature on this topic [8] some CT characteristics have been identified as relatively common to HACs, whatever their localization. According to these authors, HACs are usually large-sized 
tumors, with the same density of the normal liver at baseline scan (the presence of necrotic areas, however, often makes masses appear inhomogeneous), and moderately enhance after intravenous iodinated contrast medium administration; invasion of adjacent anatomical landmarks (such as the pleural surface for pulmonary HACs), regional lymphadenopathies and distant metastases are frequently observed. In this series, however, only one of the tumors was localized in the lung, and none of the imaging features described is considered by the authors themselves typical enough to direct the diagnosis.

The pulmonary HAC we observed (fig. 3) shares some of these CT characteristics (large size, slight inhomogeneity, adhesion to the pleura), its features being nevertheless largely nonspecific. Similar characteristics as to volume, structure and invasion of the adjacent tissues (fig. 1b, c) can be identified in the shoulder mass, which makes our case unique: to our knowledge soft-tissue HACs have never been previously described, either isolated or in association with involvement of the lung, the stomach or other organs. Moreover, serum alpha-fetoprotein in our patient was normal, which did not aid the diagnosis. On the other hand, to date this patient has experienced a better prognosis than the average of her counterparts.

In conclusion, we suggest that $\mathrm{HAC}$ - although rare - should be included in the differential diagnosis when, in patients with a normal liver (especially if serum alphafetoprotein is raised), a mass similar in histology to hepatocellular carcinoma is found at any extrahepatic location. 


\begin{tabular}{c|l|l|l}
$\begin{array}{c}\text { Case Reports in } \\
\text { Oncolady }\end{array}$ & $\begin{array}{l}\text { Case Rep Oncol 2010;3:212-217 } \\
\text { D0I: 10.1159/000317419 }\end{array}$ & Published online: July 3, 2010 & $\begin{array}{l}\text { O 2010 S. Karger AG, Basel } \\
\text { ISSN 1662-6575 } \\
\text { www.karger.com/cro }\end{array}$ \\
\hline
\end{tabular}

Fig. 1. Conventional frontal radiographic view of the left shoulder (a) shows an ill-defined scapular radiolucent area, $3 \mathrm{~cm}$ in diameter (arrows), due to erosion from soft-tissue localization of HAC. Axial MRI scans demonstrate an 8-cm well-defined partly inhomogeneous solid mass in the soft tissues of the left shoulder (asterisks), showing high signal intensity in a fat-suppressed T1-weighted sequence (b) and moderate enhancement after intravenous administration of paramagnetic contrast medium (c).

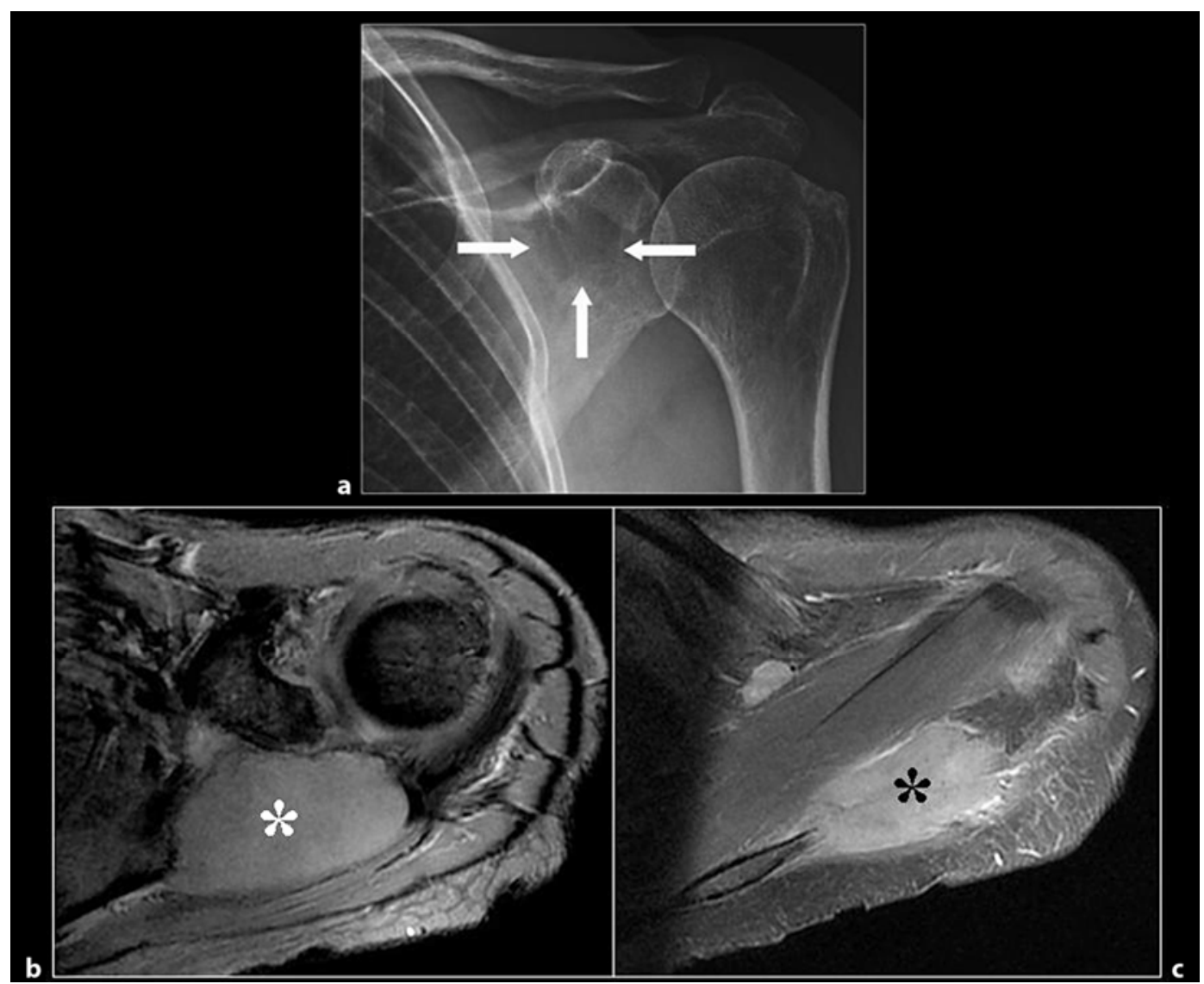




\begin{tabular}{c|l|l|l}
$\begin{array}{c}\text { Case Reports in } \\
\text { Oncolady }\end{array}$ & $\begin{array}{l}\text { Case Rep Oncol 2010;3:212-217 } \\
\text { D0I: 10.1159/000317419 }\end{array}$ & Published online: July 3, 2010 & $\begin{array}{l}\text { O 2010 S. Karger AG, Basel } \\
\text { ISSN 1662-6575 } \\
\text { www.karger.com/cro }\end{array}$ \\
\hline
\end{tabular}

Fig. 2. Fine-needle aspiration biopsy of the soft-tissue mass (hematoxylin-eosin stain). Very numerous neoplastic epithelial cells arranged in trabecular and pseudoacinar patterns, associated with biliary thrombi. The cytological findings are typical of a hepatocellular carcinoma.

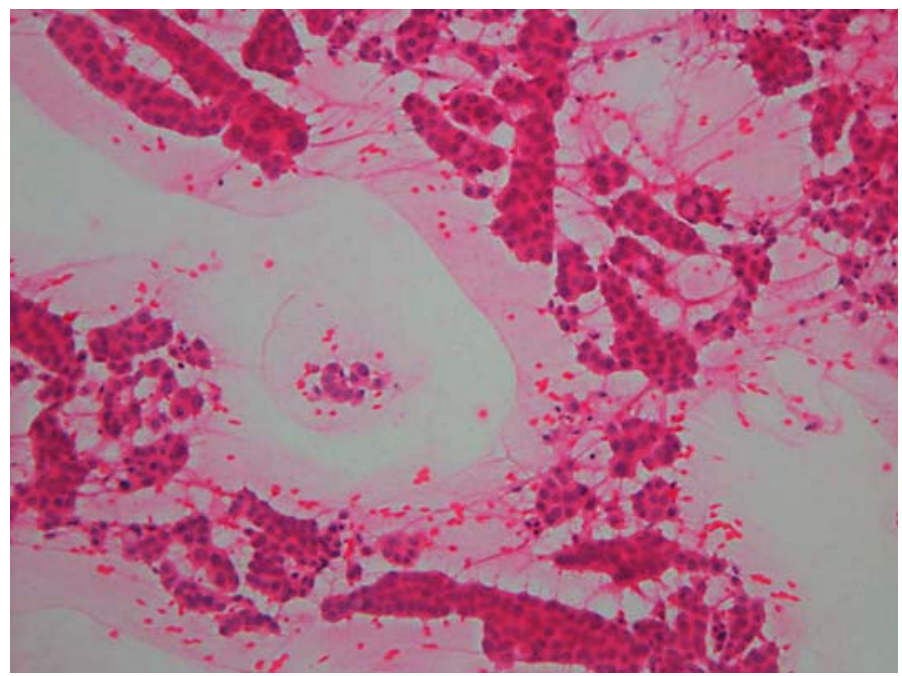

Fig. 3. (a, b). Multidetector (16-row) CT scans. $4.5 \mathrm{~cm}$ solid, partly inhomogeneous mass with pleural adhesion in the upper lobe of the left lung.

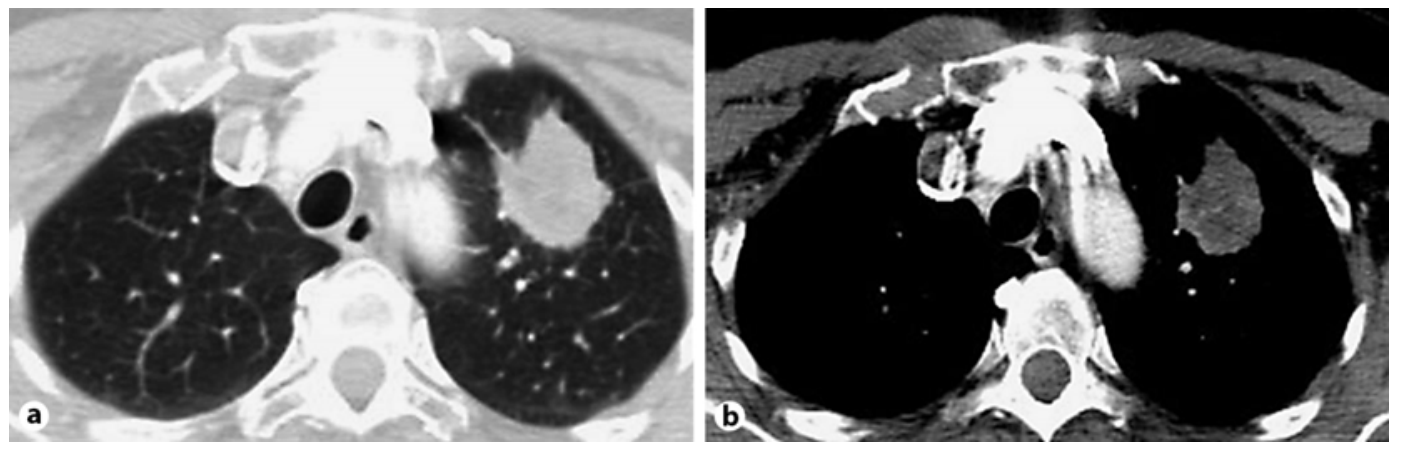




\begin{tabular}{|c|c|c|c|}
\hline $\begin{array}{l}\text { Case Reports in } \\
\text { Onatis }\end{array}$ & $\begin{array}{l}\text { Case Rep Oncol 2010;3:212-217 } \\
\text { D0I: 10.1159/000317419 }\end{array}$ & Published online: July 3, 2010 & $\begin{array}{l}\text { (c) } 2010 \text { S. Karger AG, Basel } \\
\text { ISSN } 1662-6575 \\
\text { www.karger.com/cro }\end{array}$ \\
\hline
\end{tabular}

\section{References}

1 Ishikura K, Kanda M, Ito M, Nosaka K, Mizuno K: Hepatoid adenocarcinoma: a distinctive histological subtype of alpha-fetoprotein-producing lung carcinoma. Virchows Arch A Pathol Anat Histopathol 1990;417:73-80.

-2 Terracciano LM, Glatz K, Mhawech P, Vasei M, Lehmann FS, Vecchione R, Tornillo L: Hepatoid adenocarcinoma with liver metastasis mimicking hepatocellular carcinoma: an immunohistochemical and molecular study of eight cases. Am J Surg Pathol 2003;27:1302-1312.

- 3 Arnould L, Drouot F, Fargeot P, Bernard A, Foucher P, Collin F, Petrella T: Hepatoid adenocarcinoma of the lung: report of a case of an unusual alphafetoprotein-producing lung tumor. Am J Surg Pathol 1997;21:1113-1118.

$\checkmark 4$ Nasu M, Soma T, Fukushima H, Kudo K, Matsubara O: Hepatoid carcinoma of the lung with production of alpha-fetoprotein and abnormal prothrombin: an autopsy case report. Mod Pathol 1997;10:1054-1058.

5 Carlinfante G, Foschini MP, Pasquinelli G, Scotti R, Cavazza A: Hepatoid carcinoma of the lung: a case report with immunohistochemical, ultrastructural and in-situ hybridization findings. Histopathology 2000;37:85-89.

-6 Hayashi Y, Takanashi Y, Ohsawa H, Ishii H, Nakatani Y: Hepatoid adenocarcinoma in the lung. Lung Cancer 2002;38:211-214.

-7 Oshiro Y, Takada Y, Enomoto T, Fukao K, Ishikawa S, Iijima T: A resected case of metachronous liver metastasis from lung cancer producing alpha-fetoprotein (AFP) and protein induced by vitamin K absence or antagonist II (PIVKA-II). Hepatogastroenterology 2004;51:1144-1147.

-8 Wu Z, Upadhyaya M, Zhu H, Qiao Z, Chen K, Miao F: Hepatoid adenocarcinoma: computed tomographic imaging findings with histopathologic correlation in 6 cases. J Comput Assist Tomogr 2007;31:846-852.

-9 Hiroshima K, Iyoda A, Toyozaki T, Haga Y, Baba M, Fujisawa T, Ishikura H, Ohwada H: Alpha-fetoprotein-producing lung carcinoma: report of three cases. Pathol Int 2002;52:46-53.

10 Kishimoto T, Yano T, Hiroshima K, Inayama Y, Kawachi K, Nakatani Y: A case of alpha-fetoprotein-producing pulmonary carcinoma with restricted expression of hepatocyte nuclear factor- 4 in hepatoid foci: a case report with studies of previous cases. Hum Pathol 2008;39:1115-1120.

11 Ishikura H, Kirimoto K, Shamoto M, Miyamoto Y, Yamagiwa H, Itoh T, Aizawa M: Hepatoid adenocarcinoma in the stomach. An analysis of seven cases. Cancer 1986;58:119-126.

12 Ishikura H, Scully RE: Hepatoid carcinoma of the ovary. A newly described tumor. Cancer 1987;60:2775-2784.

-13 Ishikura H, Ishiguro T, Enatsu C, Fujii H, Kakuta Y, Kanda M, Yoshiki T: Hepatoid adenocarcinoma of the renal pelvis producing alpha-fetoprotein of hepatic type and bile pigment. Cancer 1991;67:3051-3056.

14 Tanno S, Obara T, Fujii T, Izawa T, Mizukami Y, Saitoh Y, Ura H, Kohgo Y: Alpha-fetoprotein producing adenocarcinoma of the pancreas presenting focal hepatoid differentiation. Int J Pancreatol 1999;26:43-47.

15 Lopez-Beltran A, Luque RJ, Quintero A, Requena MJ, Montironi R: Hepatoid adenocarcinoma of the urinary bladder. Virchows Arch 2003;442:381-387. 